\title{
Cardiac output determination by thermodilution and arterial pulse waveform analysis in patients undergoing aortic valve replacement
}

\author{
[Détermination du débit cardiaque par thermodilution et par analyse du contour de
} pression artérielle chez des patients subissant un remplacement de la valve aortique]

Klaus Staier MD, ${ }^{*}$ Christoph Wiesenack MD $†$ Ludwig Günkel MD, $\ddagger$ Cornelius Keyl MD*

Purpose: To compare the accuracy of cardiac output (CO) measurement by arterial pulse waveform analysis $\left(\mathrm{CO}_{\mathrm{PW}}\right)$ to thermodilution assessments in patients with aortic stenosis, a high-risk patient group who may benefit from extended hemodynamic monitoring.

Methods: In 30 patients with aortic stenosis, $\mathrm{CO}$ was assessed in triplicate by thermodilution via pulmonary artery catheterization $\left(\mathrm{CO}_{\mathrm{PAC}}\right)$, and by arterial pulse waveform analysis $\left(\mathrm{CO}_{\mathrm{PW}}\right)$, before and after valve replacement. The techniques were compared by assessing the repeatability coefficient of each method and by calculating the percentage error, bias, and the limits of agreement between methods.

Results: The repeatability coefficients of $\mathrm{CO}_{\mathrm{PAC}}$ and $\mathrm{CO}_{\mathrm{PW}}$ were $0.89 \mathrm{~L} \cdot \mathrm{min}^{-1}$ and $1.04 \mathrm{~L} \cdot \mathrm{min}^{-1}$ respectively after induction of anesthesia, which corresponded to $24 \%$ of $\mathrm{CO}_{\mathrm{PAC}}$ and $26 \%$ of $\mathrm{CO}_{\mathrm{PW}}$ and increased to $33 \%$ of $\mathrm{CO}_{\mathrm{PAC}}$ and $32 \%$ of $\mathrm{CO}_{\mathrm{PW}}$ immediately after extracorporeal circulation. A systematic error between methods was not observed. The limits of agreement were bias $\pm 1.42 \mathrm{~L} \cdot \mathrm{min}^{-1}$ after anesthesia induction, corresponding to a $36 \%$ percentage error. The scattering of differences between methods increased markedly after termination of extracorporeal circulation (percentage error $56 \%$ ).

Conclusion: The repeatability of $\mathrm{CO}_{\mathrm{PAC}}$, as well as of $\mathrm{CO}_{\mathrm{PW}}$ is reduced in patients with aortic stenosis. The repeatability of both methods, as well as the agreement between methods, decreased markedly immediately after termination of cardiopulmonary bypass.
Objectif : Comparer la précision de la mesure du débit cardiaque (CO) par analyse du contour de la pression artérielle $\left(\mathrm{CO}_{P W}\right)$ aux évaluations par thermodilution chez les patients présentant une sténose aortique, un groupe de patients à haut risque qui pourraient bénéficier d'un monitorage hémodynamique étendu.

Méthode : Le CO a été mesuré en triplicata par thermodilution, via un cathéter de l'artère pulmonaire $\left(\mathrm{CO}_{\mathrm{PAC}}\right)$, et par analyse du contour de la pression artérielle $\left(\mathrm{CO}_{P W}\right)$, chez 30 patients souffrant de sténose aortique avant et après le remplacement valvulaire. Les techniques ont été comparées en évaluant le coefficient de reproductibilité de chaque méthode et en calculant le pourcentage d'erreur, le biais et les limites de la concordance des méthodes.

Résultats : Les coefficients de reproductibilité de $C O_{P A C} E T C O_{P W}$ étaient de $0,89 \mathrm{~L} \cdot \mathrm{min}^{-1}$ et $1,04 \mathrm{~L} \cdot \mathrm{min}^{-1}$ respectivement après induction de l'anesthésie, ce qui correspond à $24 \%$ de $\mathrm{CO}_{P A C}$ et $26 \%$ de $\mathrm{CO}_{P W}$ et ont augmenté à $33 \%$ de $\mathrm{CO}_{P A C}$ et $32 \%$ de $\mathrm{CO}_{P W}$ immédiatement après la circulation extracorporelle. Aucune erreur systématique entre les méthodes n'a été observée. Les limites de la concordance étaient un biais de $\pm 1,42 \mathrm{~L} \cdot \mathrm{min}^{-1}$ après l'induction de l'anesthésie, soit un pourcentage d'erreur de 36 $\%$. La distribution des différences entre les méthodes a considérablement augmenté après la fin de la circulation extracorporelle (pourcentage d'erreur $56 \%$ ).

Conclusion : La reproductibilité de $\mathrm{CO}_{P A C}$ ainsi que de $\mathrm{CO}_{P W}$ est réduite chez les patients souffrant de sténose aortique. La reproductibilité des deux méthodes, ainsi que la concordance entre les méthodes, ont considérablement diminué après la fin de la circulation extracorporelle. 
I $\mathrm{N}$ view of recurrent discussions about the usefulness and dangers of the pulmonary artery catheter (PAC), alternative techniques of hemodynamic monitoring have been developed and evaluated. ${ }^{1}$ Several devices use the analysis of the arterial pressure curve to estimate left ventricular stroke volume. However, changes in the pressure curve, due to changes in the peripheral arterial vascular tone, might influence the determination of stroke volume, as we observed in a previous study evaluating pulse contour analysis. ${ }^{2}$

Recent studies of a new method, the cardiac output $(\mathrm{CO})$ measured by pulse waveform analysis $\left(\mathrm{CO}_{\mathrm{PW}}\right)$, give inconsistent results, ${ }^{3-7}$ which may be related to the software version used, the patient populations studied, or the statistical methods used. Further investigation of this method is therefore needed. We compared $\mathrm{CO}$ measured by thermodilation via $\mathrm{PAC}$ $\left(\mathrm{CO}_{\mathrm{PAC}}\right)$, with $\mathrm{CO}_{\mathrm{PW}}$ in patients suffering from aortic stenosis who were undergoing replacement of the aortic valve. In this high risk patient population, the noninvasive assessment of stroke volume may be a valuable part of hemodynamic monitoring during surgery and intensive care. Pulse wave morphology is altered in these patients due to the underlying valvular disease, and may be further altered after valvular replacement. The influence of these phenomena on $\mathrm{CO}_{\mathrm{PW}}$ (not previously investigated) should be of interest to anesthesiologists. Accordingly, this study was undertaken to compare the repeatability of $\mathrm{CO}_{\mathrm{PW}}$ with $\mathrm{CO}_{\mathrm{PAC}}$, and to quantitate the agreement between methods during changes in $\mathrm{CO}$ and blood pressure.

\section{Methods}

The study was approved by the local Ethics Committee, and all patients gave written informed consent. Thirty subjects, 16 male, aged 45 to $81 \mathrm{yr}$ (mean age $73.6 \mathrm{yr}$, mean height $166 \pm 8 \mathrm{~cm}$, mean weight $76.6 \pm 14.1 \mathrm{~kg}$ ), who were scheduled for elective aortic valve replacement for aortic stenosis, were investigated. Patients were excluded if previous echocardiographic investigation revealed evidence of co-existent aortic regurgitation, or if the cardiac rhythm was other than normal sinus. Patients were premedicated with temazepam $10-20 \mathrm{mg}$ orally. Anesthesia was induced with sufentanil, etomidate and pancuronium, and was maintained with sevoflurane and supplemental sufentanil as required. A 20G arterial cannula (Leader-Cath ${ }^{\mathrm{TM}}$, VYGON GmbH, Aachen, Germany) was inserted into the left radial artery, and connected to the FloTrac ${ }^{\mathrm{TM}}$ sensor/Vigileo ${ }^{\mathrm{TM}}$ Monitor (Edwards LifeSciences, Irvine, CA, USA) and to the standard hemodynamic monitor (Marquette Hellige GmbH, Freiburg,
Germany). A 7 Fr PAC (Edwards LifeSciences Irvine, CA, USA) was introduced into the pulmonary artery via the right internal jugular vein. Cardiac output was measured by the conventional pulmonary artery thermodilution technique (Marquette Hellige, Freiburg, Germany), and by analysis of the pressure wave registered in the radial artery $\left(\right.$ FloTrac $^{\mathrm{TM}}$ sensor/Vigileo ${ }^{\mathrm{TM}}$ Monitor). Cardiac output, measured by thermodilution via $\mathrm{PAC}$ and $\mathrm{CO}_{\mathrm{PW}}$, was assessed by averaging the results of three measurements randomly distributed over the respiratory cycle, and carried out within a three-minute time interval. Cardiac output, measured by thermodilution via PAC, was measured using 10 $\mathrm{mL}$ cooled $0.9 \%$ sodium chloride solution injected in less than four seconds through the proximal lumen of the PAC. The measurements were accepted if the thermodilution curve showed a typical morphology without indication of artefacts. Cardiac output measured by pulse waveform analysis was calculated in time intervals of $20 \mathrm{sec}$, and was registered simultaneously with the $\mathrm{CO}_{\mathrm{PAC}}$ measurements.

Cardiac output was determined during clinical steady state conditions at four sample times: after induction of anesthesia (sample point A); after sternotomy (sample point B); five minutes after the end of extracorporeal circulation (sample point $\mathrm{C}$ ); and after closure of the chest (sample point D). Thus, we assessed CO twice before valve replacement, and twice after valve replacement, during different clinical conditions.

\section{Statistical analysis}

In previous experiments, we determined a mean $\mathrm{CO}_{\mathrm{PAC}}$ of $4.0 \mathrm{~L} \cdot \mathrm{min}^{-1}$ and a variance of $1.0\left(\mathrm{~L} \cdot \mathrm{min}^{-1}\right)^{2}$ in patients with aortic stenosis. Selecting a statistical power of 0.8 , and assuming that a bias of $0.5 \mathrm{~L} \cdot \mathrm{min}^{-1}$ between methods is of clinical relevance, (i.e., an effect size of 0.5 ) we calculated that a minimal sample size of 30 patients was required.

The coefficients of variation $(\mathrm{SD} /$ mean $\times 100 \%)$ were calculated for the triplicate $\mathrm{CO}$ determinations and were used as a measure of the scattering of methods. Additionally, the repeatability coefficient, which reports the range in which $95 \%$ of replicate measurements are expected to lie, was calculated for the three measurements in accordance with the suggestions of Bland and Altman. ${ }^{8}$ Agreement between methods was also calculated according to the method described by Bland and Altman. ${ }^{9}$ The bias between $\mathrm{CO}_{\mathrm{PAC}}$ and $\mathrm{CO}_{\mathrm{PW}}$ was calculated as the mean difference between $\mathrm{CO}$ measurements by each method. The upper and lower limits of agreement, which define the range in which $95 \%$ of the differences between methods are 
TABLE Repeatability and precision of cardiac output measurement and hemodynamic data at the different sample points. Data are reported as mean \pm SD. A $P<0.025$ is regarded as significant due to adjustment of the alpha error for repeated measurements.

\begin{tabular}{|c|c|c|c|c|c|c|}
\hline Sample point & $A$ & $B$ & $\begin{array}{l}P \text { value } \\
A \text { vs } B\end{array}$ & $C$ & $D$ & $\begin{array}{l}\text { Pvalue } \\
\text { C ps D }\end{array}$ \\
\hline $\begin{array}{l}\text { Heart rate } \\
\left(\min ^{-1}\right)\end{array}$ & $58.7 \pm 10.5$ & $69.2 \pm 12.3$ & 0.001 & $87.7 \pm 6.7$ & $88.3 \pm 3.9$ & 0.56 \\
\hline $\begin{array}{l}\text { Systolic blood pressure } \\
(\mathrm{mmHg})\end{array}$ & $108.0 \pm 17.0$ & $119.0 \pm 15.3$ & 0.005 & $114.1 \pm 13.4$ & $115.2 \pm 16.5$ & 0.75 \\
\hline $\begin{array}{l}\text { Diastolic blood pressure } \\
(\mathrm{mmHg})\end{array}$ & $52.4 \pm 8.8$ & $56.0 \pm 12.6$ & 0.049 & $59.3 \pm 8.9$ & $63.7 \pm 10.9$ & 0.027 \\
\hline $\begin{array}{l}\text { Mean blood pressure } \\
(\mathrm{mmHg})\end{array}$ & $72.3 \pm 10.7$ & $80.0 \pm 12.8$ & 0.01 & $77.8 \pm 10.2$ & $82.6 \pm 12.7$ & 0.075 \\
\hline $\begin{array}{l}\mathrm{CO}_{\text {PAC }} \\
\left(\mathrm{L} \cdot \mathrm{min}^{-1}\right)\end{array}$ & $3.77 \pm 0.83$ & $4.63 \pm 1.08$ & 0.001 & $5.14 \pm 1.45$ & $4.58 \pm 1.33$ & 0.001 \\
\hline $\begin{array}{l}\text { Cardiac index } \\
\left(\left(\mathrm{L} \cdot \mathrm{min}^{-1} \cdot \mathrm{m}^{-2}\right)\right.\end{array}$ & $2.02 \pm 0.43$ & $2.48 \pm 0.56$ & 0.001 & $2.72 \pm 0.63$ & $2.43 \pm 0.60$ & 0.001 \\
\hline $\mathrm{CV} \mathrm{CO}_{\mathrm{PAC}}$ & 6.9 & 8.9 & & 9.6 & 7.6 & \\
\hline $\begin{array}{l}\mathrm{CO}_{\text {PAC }} \\
\text { Repeatability coefficient } \\
\left(\mathrm{L} \cdot \mathrm{min}^{-1}\right)\end{array}$ & 0.89 & 1.42 & & 1.63 & 1.03 & \\
\hline $\begin{array}{l}\mathrm{CO}_{\mathrm{PW}} \\
\left(\mathrm{L} \cdot \mathrm{min}^{-1}\right)\end{array}$ & $3.93 \pm 0.66$ & $4.57 \pm 0.99$ & 0.001 & $4.88 \pm 1.07$ & $4.82 \pm 0.91$ & 0.64 \\
\hline $\begin{array}{l}\text { Cardiac index } \\
\left(\mathrm{L} \cdot \mathrm{min}^{-1} \cdot \mathrm{m}^{-2}\right)\end{array}$ & $2.10 \pm 0.24$ & $2.43 \pm 0.42$ & 0.001 & $2.60 \pm 0.51$ & $2.57 \pm 0.37$ & 0.60 \\
\hline $\mathrm{CV} \mathrm{CO}_{\mathrm{PW}}$ & 6.3 & 9.7 & & 10.8 & 6.3 & \\
\hline $\begin{array}{l}\mathrm{CO}_{\mathrm{PW}} \\
\text { Repeatability coefficient } \\
\left(\mathrm{L} \cdot \mathrm{min}^{-1}\right)\end{array}$ & 1.04 & 1.39 & & 1.60 & 1.12 & \\
\hline $\begin{array}{l}\text { Mean CO } \\
\left(\mathrm{L} \cdot \mathrm{min}^{-1}\right)\end{array}$ & $3.85 \pm 0.66$ & $4.60 \pm 0.93$ & 0.001 & $5.01 \pm 1.05$ & $4.70 \pm 1.00$ & 0.005 \\
\hline $\begin{array}{l}\text { Mean cardiac index } \\
\left(\mathrm{L} \cdot \mathrm{min}^{-1} \cdot \mathrm{m}^{-2}\right)\end{array}$ & $2.06 \pm 0.33$ & $2.45 \pm 0.42$ & 0.001 & $2.66 \pm 0.43$ & $2.50 \pm 0.41$ & 0.005 \\
\hline Bias & $0.16 \pm 0.71$ & $-0.06 \pm 0.91$ & & $-0.26 \pm 1.43$ & $0.24 \pm 1.09$ & \\
\hline$[95 \% \mathrm{CI}]\left(\mathrm{L} \cdot \mathrm{min}^{-1}\right)$ & {$[-0.11$ to 0.42$]$} & {$[-0.40$ to 0.28$]$} & & {$[-0.79$ to 0.27$]$} & {$[-0.17$ to 0.64$]$} & \\
\hline $\begin{array}{l}\text { Upper limit of agreement } \\
{[95 \% \mathrm{CI}]} \\
\left(\mathrm{L} \cdot \mathrm{min}^{-1}\right)\end{array}$ & $\begin{array}{l}1.55 \\
{[1.09 \text { to } 2.01]}\end{array}$ & $\begin{array}{l}1.72 \\
{[1.13 \text { to } 2.31]}\end{array}$ & & $\begin{array}{l}2.54 \\
{[1.62 \text { to } 3.46]}\end{array}$ & $\begin{array}{l}2.37 \\
{[1.66 \text { to } 3.08]}\end{array}$ & \\
\hline $\begin{array}{l}\text { Lower limit of agreement } \\
{[95 \% \mathrm{CI}]} \\
\left(\mathrm{L} \cdot \mathrm{min}^{-1}\right)\end{array}$ & $\begin{array}{l}-1.24 \\
{[-1.70 \text { to }-0.78]}\end{array}$ & $\begin{array}{l}-1.84 \\
{[-2.43 \text { to }-1.25]}\end{array}$ & & $\begin{array}{l}-3.06 \\
{[-3.98 \text { to }-2.14]}\end{array}$ & $\begin{array}{l}-1.90 \\
{[-2.60 \text { to }-1.19]}\end{array}$ & \\
\hline Percentage error $(\%)$ & 36 & 39 & & 56 & 46 & \\
\hline
\end{tabular}

expected to lie, were calculated as bias $\pm 1.96 \mathrm{SD}$. The precision of the bias, and of the limits of agreement, are reported as a $95 \%$ confidence interval. As the scattering of the differences between $\mathrm{CO}_{\mathrm{PAC}}$ and $\mathrm{CO}_{\mathrm{PW}}$ increased with increasing $\mathrm{CO}$, especially in the post-bypass period, bias analysis was additionally performed with logarithmically transformed data. The antilog transformed data of the limits of agreement report the range in which one method is expected to differ from the other for $95 \%$ of cases. ${ }^{9}$ Additionally, the percentage error, (1.96 SD of the bias between methods divided by the mean $\mathrm{CO}$, expressed as percentage), which is used as a measure of the relative error between methods, was calculated as proposed by Critchley and Critchley. ${ }^{10}$

Statistical analysis was performed using commercially available software (SPSS for Windows 12.0.1., SPSS Inc., Chicago, IL, USA). After the assessment of normal distribution by the Lilliefors modification of the Kolmogorov-Smirnov test, and visual assessment of the histograms and the probability plots (Q-Q plots), the two-tailed Student's $t$ test for paired 

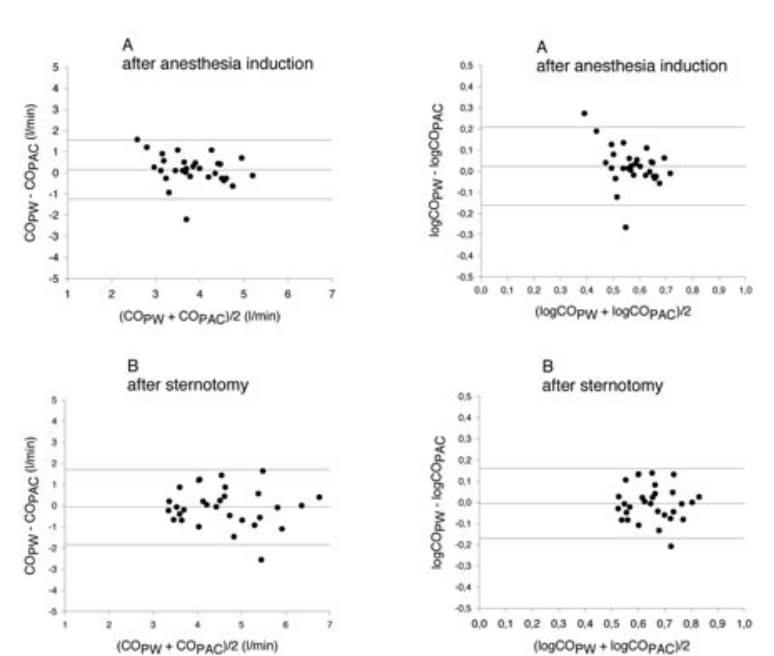

$\left(\mathrm{log} C \mathrm{OPW}_{\mathrm{PW}}+\log \mathrm{CO} \mathrm{PAC}\right) / 2$
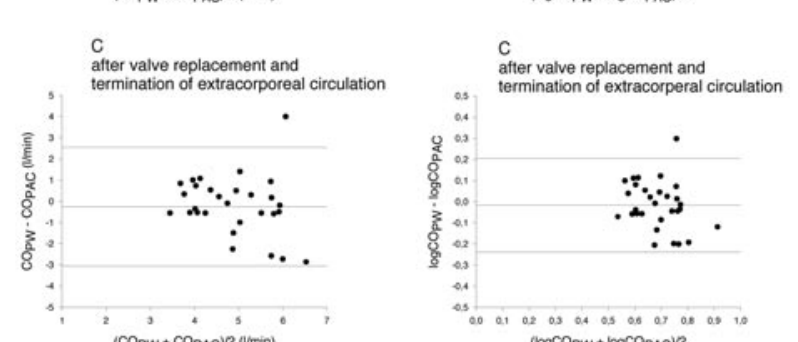

(COPW + COpacy/2(Umin)

D
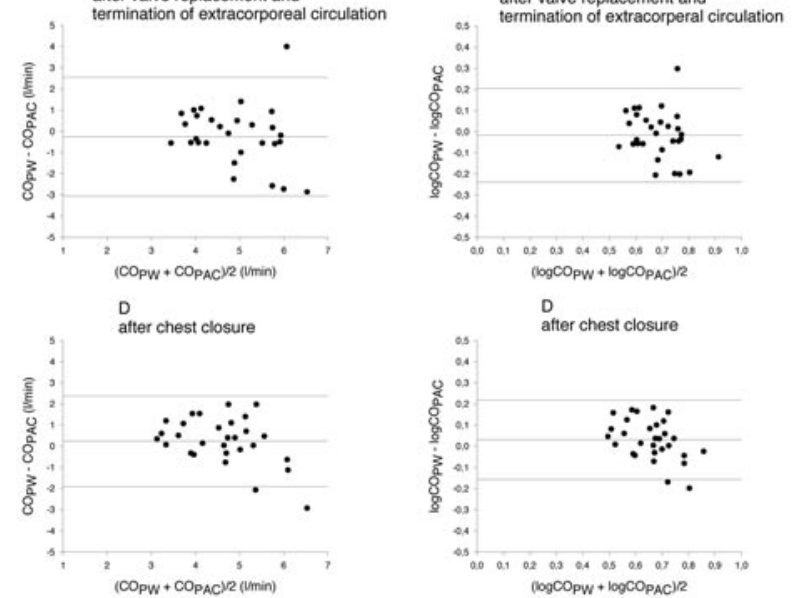

$\left(\log C \mathrm{OPW}_{\mathrm{P}}+\log _{\mathrm{CO}} \mathrm{PAC}_{\mathrm{PC}} / 2\right.$

D

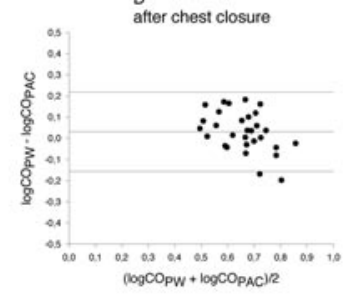

FIGURE 1 Bland-Altman analysis for $\mathrm{CO}_{\mathrm{PAC}}$ and $\mathrm{CO}_{\mathrm{PW}}$ (left) and for the logarithmic transformed data of $\mathrm{CO}_{\mathrm{PAC}}$ and $\mathrm{CO}_{\mathrm{PW}}$ (right) at the four sample points. The bias and the limits of agreement $( \pm 1.96 \mathrm{SD}$ of bias $)$ are indicated. $\mathrm{CO}_{\mathrm{PAC}}=$ cardiac output measured by thermodilution via pulmonary artery catheter; $\mathrm{CO}_{\mathrm{PW}}=$ cardiac output measured by pulse waveform analysis; $\mathrm{A}=$ after induction of anesthesia $; \mathrm{B}=$ after sternotomy $\mathrm{C}=$ five minutes after the end of extracorporeal circulation; $\mathrm{D}=$ after closure of the chest.

data was used to compare variables. A $P<0.05$ was regarded as significant. As we performed two significance tests on hemodynamic data (sample points A vs $\mathrm{B}$ and $\mathrm{C}$ vs $\mathrm{D}$ ) the alpha error was adjusted in accordance with the Bonferroni method, and a $P<0.025$ was regarded as significant for these comparisons.

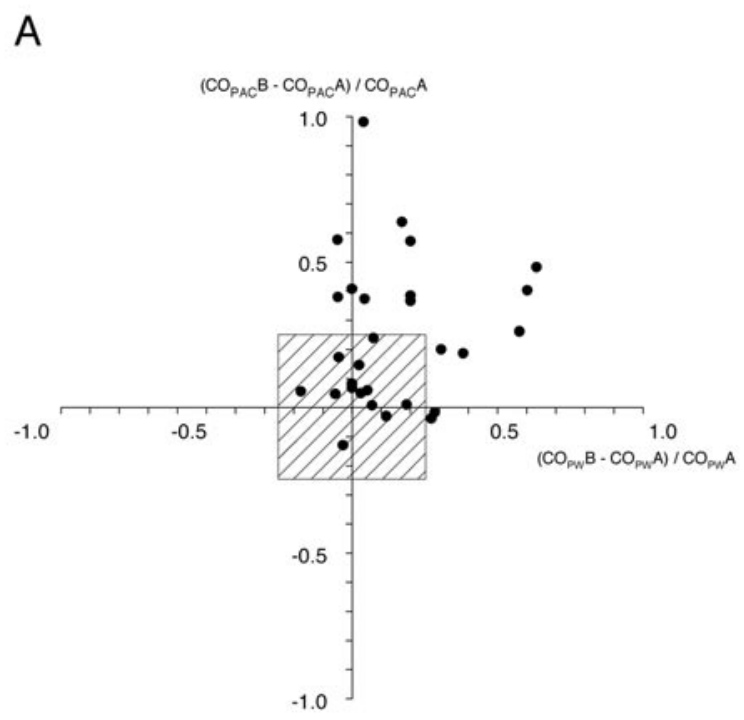

B

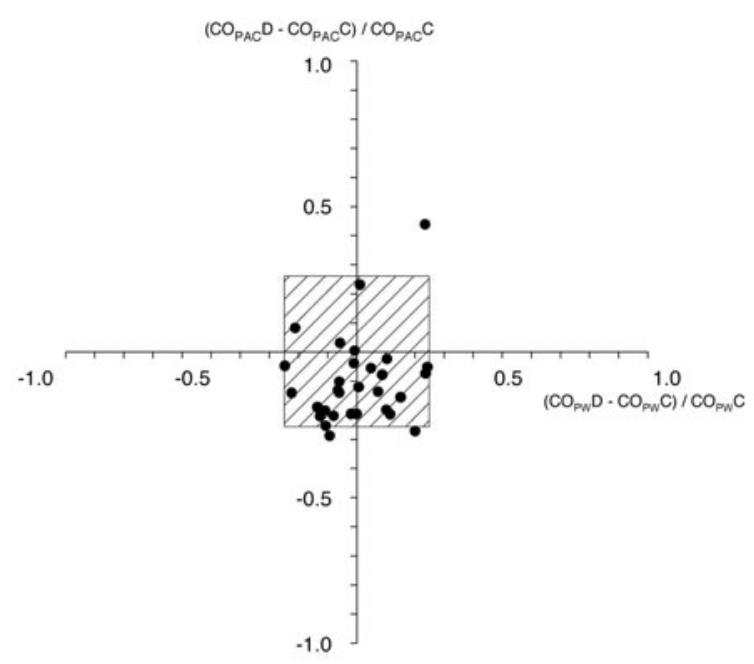

FIGURE 2 Fractional changes in $\mathrm{CO}_{\mathrm{PAC}}$ and $\mathrm{CO}_{\mathrm{PW}}$ from sample point $A$ to $B(A)$ and from sample point $C$ to $D(B)$. The shaded area marks the $25 \%$ error of methods. Refer to Figure 1 legend for abbreviations.

\section{Results}

All patients completed the study protocol. The hemodynamic data obtained at the different sample points, and the details of $\mathrm{CO}$ measurement and analysis, are reported in the Table. Heart rate, blood pressure and both $\mathrm{CO}_{\mathrm{PAC}}$ and $\mathrm{CO}_{\mathrm{PW}}$ increased significantly from sample point A to sample point B. Heart rate and 
blood pressure remained stable from sample points C to D. Cardiac output measured by pulse waveform analysis remained stable, but $\mathrm{CO}_{\mathrm{PAC}}$ decreased from C to D.

The coefficient of variation, as well as the repeatability coefficient, was lowest after induction of anesthesia, (sample point A). The repeatability coefficient of the two methods corresponded to $24 \%$ of $\mathrm{CO}_{\mathrm{PAC}}$ and $26 \%$ of $\mathrm{CO}_{\mathrm{PW}}$ at this sample point. The repeatability coefficient increased after sternotomy, (sample point B), and after termination of extracorporeal circulation, (sample point $\mathrm{C}),\left(31 \%\right.$ of $\mathrm{CO}_{\mathrm{PAC}}, 30 \%$ of $\mathrm{CO}_{\mathrm{PW}}$, and $32 \%$ of $\mathrm{CO}_{\mathrm{PAC}}, 33 \%$ of $\mathrm{CO}_{\mathrm{PW}}$, respectively). Repeatability returned to the initial values at sample point $\mathrm{D}\left(22 \%\right.$ of $\mathrm{CO}_{\mathrm{PAC}}, 23 \%$ of $\left.\mathrm{CO}_{\mathrm{PW}}\right)$.

The bias between $\mathrm{CO}_{\mathrm{PAC}}$ and $\mathrm{CO}_{\mathrm{PW}}$, and the upper and lower limits of agreement, are presented in Figure 1. The bias between $\mathrm{CO}_{\mathrm{PAC}}$ and $\mathrm{CO}_{\mathrm{PW}}$ was not significantly different from zero at all sample points. The agreement between methods was highest at sample point A with a percentage error of $36 \%$. The percentage error increased markedly at sample points $\mathrm{C}$ and D. The antilog of the limits of agreement, which reveals the extent to which the methods differ for 95\% of cases, showed that $\mathrm{CO}_{\mathrm{PAC}}$ differed from $\mathrm{CO}_{\mathrm{PW}}$ by $32 \%$ below to $61 \%$ above at sample point $\mathrm{A}$, by $33 \%$ below to $44 \%$ above at sample point B, by $58 \%$ below to $60 \%$ above at sample point $\mathrm{C}$, and by $31 \%$ below to $65 \%$ above at sample point $\mathrm{D}$. The fractional changes from $\mathrm{CO}_{\mathrm{PAC}}$ and $\mathrm{CO}_{\mathrm{PW}}$ from $\mathrm{A}$ to $\mathrm{B}$, and from $\mathrm{C}$ to $\mathrm{D}$ are presented in Figure 2. The shaded area marks the $25 \%$ error of methods. The graph demonstrates that the reference and the test method did not report changes in $\mathrm{CO}$ from $\mathrm{A}$ to $\mathrm{B}$ in opposite directions. However, increases in $\mathrm{CO}_{\mathrm{PAC}}$ were not always reflected by increases in $\mathrm{CO}_{\mathrm{PW}}$. The changes in $\mathrm{CO}$ from sample point $\mathrm{C}$ to $\mathrm{D}$ were mostly in the range of the $25 \%$ error of the methods.

\section{Discussion}

There are three main findings of the present study. Firstly, the repeatability of $\mathrm{CO}$ assessments evaluated in triplicate by $\mathrm{CO}_{\mathrm{PAC}}$ and as $\mathrm{CO}_{\mathrm{PW}}$, is limited in patients with aortic stenosis, and decreases further in the period immediately after cardiopulmonary bypass. Secondly, there is no significant bias between $\mathrm{CO}_{\mathrm{PAC}}$ and $\mathrm{CO}_{\mathrm{PW}}$ assessments. Finally, the percentage error between $\mathrm{CO}_{\mathrm{PAC}}$ and $\mathrm{CO}_{\mathrm{PW}}$ methods of assessment is about $35 \%$ in patients with aortic stenosis. After extracorporeal circulation, the agreement between methods decreases markedly.
The repeatability of $C O_{P A C}$ and $C O_{P W}$

Based on the data from 14 clinical studies, Stetz and coworkers ${ }^{11}$ calculated that the error of $\mathrm{CO}$ determination by the thermodilution technique was $22 \%$ for single measurements and $13 \%$ for the average of triplicate measurements. These results were supported by Mackenzie and colleagues ${ }^{12}$ who found that the 95\% confidence limit for $\mathrm{CO}$ determination by thermodilution had a value between $21 \%$ and $33 \%$ of CO under in vitro conditions with a pulsatile flow of 5 $\mathrm{L} \cdot \mathrm{min}^{-1}$. According to the study by MacKenzie, ${ }^{12}$ the physiological limit of precision for CO measurement by thermodilution has frequently been reported with $1 \mathrm{~L} \cdot \mathrm{min}^{-1}$. Based on these calculations, it has been proposed that the limits of agreement between a new technique for the determination of $\mathrm{CO}$ and thermodilution as the gold standard should not exceed the 10$20 \%$ error of the thermodilution method. ${ }^{13}$ However, Critchley pointed out that it is advisable to combine the errors of the test and the reference method, and calculated a value of $28 \% .{ }^{10}$

In the present study, we observed a repeatability coefficient of about $1 \mathrm{~L} \cdot \mathrm{min}^{-1}$ at the sample points $\mathrm{A}$ and $\mathrm{D}$ for both methods. However, these patients with severe aortic stenosis had COs which were clearly lower than the mentioned reference value of 5 $\mathrm{L} \cdot \mathrm{min}^{-1}$, resulting in a relative error of about $25 \%$. As a consequence, the reproducibility of CO determination was decreased in our patients with aortic stenosis when compared to previously published data. ${ }^{10,11,13}$

In addition, methodological limitations may have contributed to this phenomenon, as the three measurements of $\mathrm{CO}$ were randomly distributed over the respiratory cycle. This approach is associated with an increase in the physiological error of $\mathrm{CO}$ measurement. Stevens et al..$^{14}$ observed that the coefficient of variation was greater than $10 \%$ if the injections for the measurement of $\mathrm{CO}$ were randomly distributed over the respiratory cycle, compared to $4 \%$ for the injection in the expiratory pause. On the other hand, a method which averages the stroke volume over a time period of $20 \mathrm{sec}$, such as arterial pulse waveform analysis, should not show this dependence on the respiratory cycle.

After termination of extracorporeal circulation, the repeatability of $\mathrm{CO}$ determination decreased further. An increasing error in $\mathrm{CO}$ determination by thermodilution may have been caused by shifts in blood temperature, a well-known phenomenon after cardiopulmonary bypass. ${ }^{15}$ However, decreased reproducibility was likewise observed in $\mathrm{CO}_{\mathrm{PW}}$, which should not be influenced by blood temperature. It is possible that the decrease in reproducibility may be attributed to changes in hemodynamic conditions immediately after 
termination of extracorporeal circulation, even under the clinical impression of steady state conditions. This assumption is supported by the fact that the repeatability coefficient returned to the initial value after sternal closure, (i.e., about 15 to $30 \mathrm{~min}$ after sample point C). Our results underline the well-known inaccuracies when determining $\mathrm{CO}$ in the period after cardiopulmonary bypass, regardless of the method used.

Bias between $C O_{P A C}$ and $C O_{P W}$

In a previous study we observed that increases in blood pressure, due to an increase in peripheral resistance, caused an erroneous increase in the estimation of $\mathrm{CO}$ by pulse contour analysis. ${ }^{2}$ This phenomenon caused a marked bias to $\mathrm{CO}_{\mathrm{PAC}}$, and may be explained by changes in arterial input impedance influencing the contour of the pulse wave. ${ }^{16}$ The current device estimates $\mathrm{CO}$ by analyzing the pulse waveform without individual calibration. ${ }^{17}$ In the present study, we did not observe a significant bias between $\mathrm{CO}_{\mathrm{PAC}}$ and $\mathrm{CO}_{\mathrm{PW}}$ at any sample point despite the blood pressure increasing significantly from sample point A to B. Additionally, changes in the morphology of the arterial pressure curve, before and after valve replacement, did not cause any systematic error between methods. Cardiac output measured by thermodilution via PAC was slightly increased, compared to $\mathrm{CO}_{\mathrm{PW}}$, after termination of extracorporeal circulation; but the bias was not significantly different from zero. An overestimation of $\mathrm{CO}_{\mathrm{PAC}}$ in the immediate period after termination of cardiopulmonary bypass has been reported by other authors when comparing thermodilution with Doppler - CO. ${ }^{18}$ As already mentioned above, instability of blood temperature was discussed as the cause of the inaccuracy of $\mathrm{CO}$ measurement by thermodilution in the post-bypass period. ${ }^{18}$

\section{The precision of $\mathrm{CO}$ determination by $\mathrm{CO}_{P A C}$ and $C O_{P W}$}

It has been proposed that the limits of agreement between a new technique for the determination of $\mathrm{CO}$ and thermodilution as the gold standard should not exceed the $10-20 \%$ error of the thermodilution method. ${ }^{13}$ However, Critchley and Critchley ${ }^{10}$ pointed out that the combined error of two methods can be calculated from the error of each method following a Pythagorean approach. Referring to an inherent error of $20 \%$, Critchley and Critchley stated that the limits of agreement between a reference and a test method should be lower than $30 \%$, in order to accept the methods as interchangeable. Due to the fact that the inherent error of thermodilution was increased to about $25 \%$ in our patients with aortic stenosis, a percentage error between methods of $36 \%$ should be acceptable. However, one should be aware of the large relative limits of agreement between methods calculated with the logarithmically transformed data.

In the post-bypass period the combined error would be expected to be in the range of $45 \%$, according to the criterion suggested by Critchley and Critchley. ${ }^{10}$ The actually observed percentage error of $56 \%$ indicates lack of agreement between methods post-bypass, which is underlined by the rather large relative limits of agreement. Thus, our study indicates poor agreement between the methods after extracorporeal circulation, which is at least partly related to the poor repeatability of the methods in this period.

\section{Comparison with previous studies evaluating pulse waveform analysis}

Several previous studies demonstrated a significant bias and large limits of agreement when comparing $\mathrm{CO}_{\mathrm{PAC}}$ and $\mathrm{CO}_{\mathrm{PW}}$ in the cardiac surgery setting. ${ }^{3-5}$ Whereas Opdam et al. ${ }^{3}$ analyzed repeated measures of only six postoperative cardiac surgery patients, Mayer et $a l^{5}$ investigated 40 cardiac surgery patients and found a percentage error of $46 \%$ for all confidence interval data (mean $\mathrm{CI}_{\mathrm{PAC}} 2.3 \mathrm{~L} \cdot \mathrm{min}^{-1} \cdot \mathrm{m}^{-2}$, mean $\left.\mathrm{CI}_{\mathrm{PW}} 2.8 \mathrm{~L} \cdot \mathrm{min}^{-1} \cdot \mathrm{m}^{-2}\right)$ and a bias $\pm \mathrm{SD}$ of $0.46 \pm 1.15$ $\mathrm{L} \cdot \mathrm{min}^{-1} \cdot \mathrm{m}^{-2}$. Obviously, the error of $\mathrm{CO}$ measurement increased proportionally to the magnitude of CO. The percentage error between methods increased up to $51 \%$ when analyzing a subgroup with low CO. ${ }^{5}$ Sander et al. ${ }^{4}$ studied 30 patients during coronary bypass surgery and observed a maximum bias of 1 $\mathrm{L} \cdot \mathrm{min}^{-1}\left(\mathrm{SD} \pm 1.8 \mathrm{~L} \cdot \mathrm{min}^{-1}\right)$ after sternotomy, (mean $\mathrm{CO}_{\mathrm{PAC}} 5.7 \mathrm{~L} \cdot \mathrm{min}^{-1}$, mean $\mathrm{CO}_{\mathrm{PW}} 4.7 \mathrm{~L} \cdot \mathrm{min}^{-1}$ ), which corresponded to a percentage error of $70 \%$. In contrast to these results, we did not find a significant bias between the methods. Our data demonstrate a marked improvement in precision, halving the limits of agreement, and reducing the percentage error up to $36 \%$ after anesthesia induction. The improvement in the agreement of methods may be caused by a software modification in the pulse waveform analysis which was not available in the above-mentioned studies.

Manecke and coworkers ${ }^{6}$ investigated the same improved algorithm of arterial pulse wave analysis in postoperative cardiac surgical patients, and observed a minimal bias between methods and an SD of the bias of $0.98 \mathrm{~L} \cdot \mathrm{min}^{-1}$. McGee and colleagues ${ }^{7}$ compared repeated measurements of $\mathrm{CO}_{\mathrm{PAC}}$ and $\mathrm{CO}_{\mathrm{PW}}$ in a heterogeneous patient group and calculated a bias of $0.20 \mathrm{~L} \cdot \mathrm{min}^{-1}$ and a SD of the bias of $\pm 1.28 \mathrm{~L} \cdot \mathrm{min}^{-1}$, which was interpreted as an acceptable agreement between methods. The data demonstrate an increase 
in the scattering of the differences between $\mathrm{CO}_{\mathrm{PAC}}$ and $\mathrm{CO}_{\mathrm{PW}}$ with increasing $\mathrm{CO}$, which limits the significance of the calculated agreement between methods. ${ }^{7}$ It is not known whether the authors corrected for the repeated measurement of $\mathrm{CO}$ as suggested by Bland and Altman. ${ }^{8}$

When compared to the results of Manecke, ${ }^{6}$ our data demonstrate a slightly improved agreement between methods in the period before extracorporeal circulation, and similar results in the period after sternal closure. The results reported by McGee et al. ${ }^{7}$ seem to be comparable to the analysis of the percentage error and the limits of agreement of log-transformed data which we obtained at sample points A and B.

In contrast to previously reported criteria for the thermodilution method, we found that in patients with aortic stenosis, repeatability of both $\mathrm{CO}_{\mathrm{PAC}}$ and $\mathrm{CO}_{\mathrm{PW}}$ is reduced. A systematic error between methods was not observed. These results indicate that the alteration of arterial pulse wave morphology due to aortic stenosis does not have an adverse impact on the precision of $\mathrm{CO}$ estimation. The repeatability of both methods, as well as the agreement between methods, decreased markedly after termination of cardiopulmonary bypass. These data underline the difficulty in obtaining $\mathrm{CO}$ values that are stable and accurate during this period of increased hemodynamic fluctuations. In conclusion, our study indicates that arterial pulse waveform analysis may be useful in providing extended hemodynamic monitoring from existing arterial lines in high risk patients with aortic stenosis.

\section{Acknowledgement}

The authors are very grateful to Justine Rochon, Centre of Biometrics and Statistics, University Hospital Regensburg, for her assistance.

\section{References}

1 Pinsky MR. Hemodynamic monitoring over the past 10 years. Crit Care 2006; 10: 117.

2 Rodig G, Prasser C, Keyl C, Liebold A, Hobbhabn J. Continuous cardiac output measurement: pulse contour analysis vs thermodilution technique in cardiac surgical patients. Br J Anaesth 1999; 82: 525-30.

3 Opdam HI, Wan L, Bellomo R. A pilot assessment of the FloTrac(TM) cardiac output monitoring system. Intensive Care Med 2007; 33: 344-9.

4 Sander M, Spies CD, Grubitzsch H, Foer A, Muller M, von Heymann C. Comparison of uncalibrated arterial waveform analysis in cardiac surgery patients with thermodilution cardiac output measurements. Crit Care 2006; 10: R164.

5 Mayer J, Boldt J, Schollhorn T, Rohm KD, Mengistu
AM, Suttner S. Semi-invasive monitoring of cardiac output by a new device using arterial pressure waveform analysis: a comparison with intermittent pulmonary artery thermodilution in patients undergoing cardiac surgery. Br J Anaesth 2007; 98: 176-82.

6 Manecke GR Jr, Auger WR. Cardiac output determination from the arterial pressure wave: clinical testing of a novel algorithm that does not require calibration. J Cardiothorac Vasc Anesth 2007; 21: 3-7.

$7 \mathrm{McGee}$ WT, Horswell JL, Calderon J, et al. Validation of a continuous, arterial pressure-based cardiac output measurement: a multicenter, prospective clinical trial. Crit Care 2007; 11: R105.

8 Bland JM, Altman DG. Measuring agreement in method comparison studies. Stat Methods Med Res 1999; 8: 135-60.

9 Bland JM, Altman DG. Statistical methods for assessing agreement between two methods of clinical measurement. Lancet 1986; 1: 307-10.

10 Critchley LA, Critchley JA. A meta-analysis of studies using bias and precision statistics to compare cardiac output measurement techniques. J Clin Monit Comput 1999; 15: 85-91.

11 Stetz CW, Miller RG, Kelly GE, Raffin TA. Reliability of the thermodilution method in the determination of cardiac output in clinical practice. Am Rev Respir Dis 1982; 126: 1001-4.

12 Mackenzie JD, Haites NE, Rawles JM. Method of assessing the reproducibility of blood flow measurement: factors influencing the performance of thermodilution cardiac output computers. Br Heart J 1986; 55 : 14-24.

13 LaMantia KR, O'Connor T, Barash PG. Comparing methods of measurement: an alternative approach. Anesthesiology 1990; 72: 781-3.

14 Stevens JH, Raffin TA, Mibm FG, Rosenthal MH, Stetz $C W$. Thermodilution cardiac output measurement. Effects of the respiratory cycle on its reproducibility. JAMA 1985; 253: 2240-2.

15 Latson TW, Whitten CW, O'Flaherty D. Ventilation, thermal noise, and errors in cardiac output measurements after cardiopulmonary bypass. Anesthesiology 1993; 79: 1233-43.

16 O'Rourke MF. Vascular impedance in studies of arterial and cardiac function. Physiol Rev 1982; 62: 570-623.

17 Headley JM. Arterial pressure-based technologies: a new trend in cardiac output monitoring. Crit Care Nurs Clin North Am 2006; 18: 179-87.

18 Zhao X, Mashikian JS, Panzica P, Lerner A, Park KW, Comunale $M E$. Comparison of thermodilution bolus cardiac output and Doppler cardiac output in the early post-cardiopulmonary bypass period. J Cardiothorac Vasc Anesth 2003; 17: 193-8. 